\title{
Interaction Effect of Selected Science Process Skills Acquisition on Students' Academic Performance in Practical Biology in Calabar Education Zone, Cross River State of Nigeria
}

\author{
Stephen Adah ${ }^{1}$ * $\quad$ Uwa Nsikhe ${ }^{2}$ \\ 1.Department of Curriculum \& Instructional Technology, Cross River University of Technology, PMB 1123, \\ Calabar, Cross River State, Nigeria \\ 2.Department of Biology, School of Sciences Cross River State college of Education, Akamkpa, Cross River \\ State, Nigeria
}

\begin{abstract}
The study explored the interaction effect of selected science process skills of drawing, observing, classifying, measurement and problem-solving on students' academic performance in Practical Biology in Calabar Zone of Cross River State, Nigeria. The study employed a quasi-experimental design of pretest-posttest non-equivalent intact class. One Hundred and Ninety Senior Secondary One (SS1) Biology students drawn from a target population of 5218 participated in the study. One research question guided the study and one null hypothesis was tested at 0.05 level of significance. Three secondary schools selected from 81 public secondary schools using simple random sampling of balloting with replacement were used for the study. Two research instruments tagged Science Process Skills Acquisition Test (SPSAT) and Practical Biology Performance Test (PBPT) was sources for data collection. The reliability indices of the instruments established via Cronbach alpha gave 0.812 and 0.815 respectively. Data obtained were analyzed using Analysis of Covariance (ANCOVA). The results showed significant interaction effect of acquired science process skills of classifying, measuring, and problem solving on students' academic performance in Practical Biology. However, the interaction was not significant for science process skills of drawing and observing. On the basis of the results, recommendations were made among which is that biology teachers should imbibe classroom practices that will enhance acquisition of all process skills to bring about improved academic performance in Practical Biology.
\end{abstract}

Keyword: Science Process Skills, Students’ Academic Performance, Practical Biology

DOI: $10.7176 / \mathrm{JEP} / 11-29-05$

Publication date:October $31^{\text {st }} 2020$

\section{Introduction}

The Nigerian society has been yearning to promote the quality of life of the citizenry through knowledge acquisition in science and technology. This has made it imperative to improve science teaching and learning through functional education. The study of science and technology has been recognized all over the world as a major tool for technological advancement. This is because knowledge and skills in science subjects is very vital in the development of any society (Bena, 2010). Nwankwo (2015) stressed that the development of any nation requires that her citizens should be adequately improved to contribute meaningfully and appropriately as responsible and productive citizens, and that this could only be achieved if science teaching is taught through process approach. According to the author, process approach to science will give students a sense of belonging, increase participation, a sustained interest in science as well as opportunity to acquire science process skills.

According to Ozgelen (2012), science process skills involve a collection of competencies and abilities that make possible the establishment of knowledge about the nature and concepts of science through scientific investigation. The American Association for the Advancement of Science (AAAS), (1989) developed a programme known as Science a Process Approach (SAPA) to improve student's skills in the process of science. Ango (2002) stressed that science students at early stage in schools should be give opportunity to explore and observe the wonders of science through practical activities in order to gain basic knowledge of science process skills. The Nigerian Educational Research and Development Council (NERDC) as quoted by Nwagbo (2008), came up with fifteen (15) science process skills, namely; observing, drawing, classifying, identifying, predicting, measuring, communicating, inferring, using space/ time relationship, questioning, controlling variables, defining operationally, formulating model, hypothesizing, designing experiment and interpreting data.

Richard (2013) advocated for skill acquisition in science with emphasis on practical work in biology such that students are given appropriate opportunities to make observations, design and carryout experiments including appropriate form of measurement to test explanations. Daramola and Olutola (2016) examined the effects of some selected science process skills on students' academic performance in Practical biology in Ilorin, Nigeria and came up with a suggestion that students should be given opportunity to explore the world of biology by using science process skills of manipulating, drawing, classifying, inferring, interpreting, measuring, observing and possibly problem-solving skills as they have a significant contribution to students' academic life. Aka and Aydogdu (2010) 
investigated the effects of measurement among other integrated science process skills on students' academic achievement in Turkey University reported no significant effect on students' achievement. Raj and Devi (2014) stated that science process skills are vital in the teaching learning of Chemistry, Biology and Physics at secondary school level, hence; students should be encouraged and given opportunity to handle and manipulate materials and equipment in the laboratories in order to test their ideas experimentally. Eric (2013) examined the effects of selected science process skills on students' academic performance in biology practicals in Bungoma West District, Western Kenya. Descriptive survey research design was employed for the study. Findings of the study showed that strategies adopted in helping students to acquire science process skills of drawing, measuring, identifying, classifying, and inferring of biological specimens were inadequate. Eric further stressed that the problems encountered in making drawings, measuring as well as inferring by students and the strategies used by teachers to develop those skills in students have a significant effect on their academic performance in practical biology.

Some studies have shown that science students generally exhibit poor knowledge of science process skills. For example, a study carried out by Kamba, Giwa, Libeta and Wakkla (2018) shows the mean levels of students' knowledge of SPS thus; observing $\mathrm{x}=1.59$, measuring, $\mathrm{x}=1.44$, classifying $\mathrm{x}=1.23$, predicting $\mathrm{x}=1.4$, communicating $x=1.3$ with overall mean average of 1.39. The findings of Ibe and Nwosu (2003) indicated low knowledge level and acquisition of inferring and predicting skills among senior secondary one (SS1) biology students. The poor knowledge level and acquisition of science process skills, according to Ibe and Nwosu may partly be due to lack integration of theoretical science content with practical activities by science teachers in the course of presenting science instructions. Added to this, the instructional strategies and materials in which students are exposed to may not have been providing opportunity for activity-based learning which has led to deteriorating performance in science practical examination over the years. Once students are taught without adequate practical activities which provide knowledge and acquisition of science skills they are most likely to perform poorly in practical examinations. The concern of this study therefore is to explore the extent to which selected science process skills of observing, classifying, measuring, and problem-solving affects students' academic performance in practical biology in Calabar Education Zone of Cross River State, Nigeria.

\section{Statement of the problem}

Biology as a science of living and non-living things has an important role to play in our day to day life. It is one of the key science subjects for senior secondary school curriculum with its relevance across every aspect of human endeavor. This underscores its vital recognition in the advancement of science and technology. The objectives of biology cannot be attain without its practicals, as its wide application in the area of agriculture, genetic engineer, biochemistry, food and nutrition is of great benefit to every nation of the world.

Despite the relevance of biology to technological, scientific and societal development, evidences abound that students' academic performance in biology is still not encouraging. Research reports showed that poor performance in biology could be as a result of students and teachers attitude towards practical biology, method of teaching concepts in biology, non-acquisition and utilization of science process skills. This has been of great concern to educationist, science educators, government and stakeholders, in education sector and the general public. This has undoubtedly thwarted students' efforts towards offering courses like Medicine, Biochemistry, Pharmacy, and Biotechnology in the universities. In spite of government efforts towards improving academic performance in secondary schools and ensuring adequate acquisition of science process skills, students still perform below expectation mostly in practical aspects of biology. Different strategies adopted by government and teachers have not substantially address the problem. There is therefore the need to further explore other possible innovative approach that may help curb students' poor performance in practical biology. Therefore, the problem of the present study put in question is, would acquisition of selected science process skills have interaction effect on students' academic performance in practical biology in Calabar Education Zone of Cross River State, Nigeria?

\section{Purpose of the study}

The study sought to examine the effect of selected science process skills acquisition on students' academic performance in practical biology in Calabar metropolis. Specifically, the study investigated the interaction effect of observing, measuring, classifying, and problem-solving on students' academic performance in practical biology.

\section{Research question}

One research question guided the study and it stated that what is the interaction effect of acquired science process skills of observing, measuring, classifying, and problem-solving on students' academic performance in practical biology?

\section{Hypothesis}

Acquisition of science process skills of observing, measuring, classifying, and problem-solving do not have significant interaction effect on students' academic performance in practical biology. 


\section{Methodology}

The study adopted a pretest-posttest intact class quasi-experimental design. The study was conducted in Calabar Education Zone of Cross River State, Nigeria. The study population comprised of 5218 SS1 students drawn from eighty one (81) public secondary schools in the study area. Stratified and purposive sampling techniques were employed in this study. Out of the 81 schools in the area, 3 were purposively selected and used for the study.

One hundred and ninety (190) SS1 biology students were used for the study and intact class was ensured. Two research instruments were used in gathering data for the study. These are Practical Biology Performance Test (PBPT) and Science Process Skills Acquisition Test (SPSAT). PBPT was design to measure students' academic performance in practical biology with twenty items while SPSAT was to measure the extent to which students acquire the skill in order to function effectively in science classes. It was designed with 18 items based on the skills used in the study. The validity of the instruments was reached by experts from biology and measurement and evaluation departments all in Cross River University of Technology, Calabar. The reliability estimate of .815 and .812 were reached for PBPT and SPSAT respectively using cronbach alpha. A pretest was given and data collected. After three weeks treatment, posttest was given. Data collected for pre and posttest were subjected to analysis of covariance (ANCOVA) and results presented in Table 1.

Table 1

Four Way ANCOVA Results of Interaction Effects of Science Process Skills on Students' Academic Performance in Practical Biolooy N=190

\begin{tabular}{|c|c|c|c|c|c|}
\hline Source & $\begin{array}{l}\text { Type 111 Sum } \\
\text { Of squares }\end{array}$ & Df & Mean Square & $\mathbf{F}$ & Sig \\
\hline \multicolumn{6}{|l|}{ Corrected } \\
\hline Model & 41411.454 & 48 & 862.739 & 7.152 & .000 \\
\hline Intercept & 15228.072 & 1 & 15228.072 & 126.239 & .000 \\
\hline ATPRE & 3603.749 & 1 & 3603.749 & 29.875 & .000 \\
\hline \multicolumn{6}{|l|}{ Observing } \\
\hline $\begin{array}{l}\text { Post categorize } \\
\text { Measuring }\end{array}$ & 645.457 & 2 & 322.729 & 2.675 & .072 \\
\hline $\begin{array}{l}\text { Post categorize } \\
\text { Classifying }\end{array}$ & 443.447 & 2 & 221.723 & 1.838 & .163 \\
\hline $\begin{array}{l}\text { Post categorize } \\
\text { Problem-solving }\end{array}$ & 75.491 & 2 & 37.746 & .313 & .732 \\
\hline Post categorize & 815.253 & 2 & 407.626 & 3.379 & .037 \\
\hline obspct*measpct & 166.926 & 4 & 41.731 & .346 & .846 \\
\hline obspct*classpct & 231.323 & 3 & 77.108 & .639 & .591 \\
\hline obspct*pspct & 1209.970 & 4 & 302.492 & 2.508 & .045 \\
\hline measpct*classpct & 463.668 & 4 & 115.917 & .961 & .431 \\
\hline measpct*pspct & 958.114 & 4 & 239.528 & 1.986 & .100 \\
\hline $\begin{array}{l}\text { classpct*pspct } \\
\text { obspct*measpct* }\end{array}$ & 281.892 & 4 & 70.473 & .584 & .675 \\
\hline $\begin{array}{l}\text { classpct } \\
\text { obspct*measpct* }\end{array}$ & 61.038 & 3 & 20.346 & .169 & .917 \\
\hline $\begin{array}{l}\text { pspct } \\
\text { obspct*classpct* }\end{array}$ & 521.017 & 5 & 104.203 & .864 & .507 \\
\hline $\begin{array}{l}\text { pspct } \\
\text { measpct*claspct* }\end{array}$ & .249 & 1 & .249 & .002 & .964 \\
\hline $\begin{array}{l}\text { pspct } \\
\text { obspct*measpct* }\end{array}$ & 979.865 & 3 & 326.622 & 2.708 & .048 \\
\hline classpct*pspct & 9.784 & 1 & 9.784 & .081 & .778 \\
\hline Error & 17008.620 & 141 & 120.629 & & \\
\hline Total & 480860.500 & 190 & & & \\
\hline Corrected total & 58420.074 & 189 & & & \\
\hline
\end{tabular}

a. $\quad$ R squared $=.709$ (Adjusted Squared $=.610$ )

P-values $(.000, .000, .000, .037, .045 \& .048)$ associated with the computed F-vales $(7.152,126.239$, $29.875,3.379,2.508 \& 2.708$ ) for corrected model, intercept, covariate, science process skills interaction between observing and problem-solving as well as measurement, classification, and problem-solving skills on posttest scores are all less than .05 . Since the values are all less than the chosen .05 , the null hypothesis stands rejected. This implies that there are significant main and interaction effects of science process skills on students' academic performance in practical biology. 
Table 1 further shows that the computed F-values $(2.675,1.838, .313, .346, .639, .961,1.986, .584, .169, .864, .002$, $\& .081)$ associated with the p-values $(.072, .163, .732, .846, .591, .431, .100, .675, .917, .507, .964 \& .778)$ are all higher than .05 . Hence, no main and interaction effects are recorded. The effect of covariate was removed and pretest as well as posttest scores adjusted through first principle of simple linear regression as results presented in Table 2 .

Table 2

Four Way ANCOVA Adjusted Results of Interaction Effects of Science Process Skills on Students' Academic Performance in Practical Biology N=190

\begin{tabular}{|c|c|c|c|c|c|}
\hline Source & $\begin{array}{l}\text { Type III sum } \\
\text { Of squares }\end{array}$ & Df & Mean Square & $\mathrm{F}$ & Sig. \\
\hline \multicolumn{6}{|l|}{ Corrected } \\
\hline Model & 2264.914 & 47 & 56.700 & 1.167 & .244 \\
\hline Intercept & 102495.888 & 1 & 102495.888 & 2109.252 & .000 \\
\hline Observing & & & & & \\
\hline $\begin{array}{l}\text { Post cat. } \\
\text { Measuring }\end{array}$ & 204.620 & 2 & 102.310 & 2.105 & .126 \\
\hline $\begin{array}{l}\text { Post cat. } \\
\text { Classifying }\end{array}$ & 127.293 & 2 & 63.647 & 1.310 & .273 \\
\hline $\begin{array}{l}\text { Post cat. } \\
\text { Problem-solving }\end{array}$ & 216.479 & 2 & 108.240 & 2.227 & .112 \\
\hline Post cat. & 22.371 & 2 & 11.186 & .230 & .795 \\
\hline Obspct*measpct & 129.302 & 4 & 32.325 & .665 & .617 \\
\hline Obspct*classpct & 8.035 & 3 & 2.678 & .055 & .983 \\
\hline Obspct*pspct & 177.878 & 4 & 44.470 & .915 & .457 \\
\hline Measpct*classpct & 322.221 & 4 & 80.555 & 1.658 & .163 \\
\hline Measpct*pspct & 153.749 & 4 & 38.437 & .796 & .533 \\
\hline $\begin{array}{l}\text { Classpct*pspct } \\
\text { Obspct*measpct* }\end{array}$ & 39.944 & 4 & 9.986 & .206 & .935 \\
\hline $\begin{array}{l}\text { pspct } \\
\text { Obspct*measpct* }\end{array}$ & 187.265 & 5 & 37.453 & .771 & .572 \\
\hline $\begin{array}{l}\text { pspct } \\
\text { Obspct*classpct* }\end{array}$ & 101.172 & 3 & 33.724 & .694 & .557 \\
\hline $\begin{array}{l}\text { pspct } \\
\text { Measpct*classpct* }\end{array}$ & 148.953 & 1 & 148.953 & 3.065 & .082 \\
\hline $\begin{array}{l}\text { pspct } \\
\text { Obspct*measpct* }\end{array}$ & 431.048 & 3 & 143.683 & 2.957 & .035 \\
\hline classpct*pspct & 41.728 & 1 & 41.728 & .859 & .356 \\
\hline Error & 6900.275 & 142 & 48.593 & & \\
\hline Total & 432005.615 & 190 & & & \\
\hline Corrected total & 9565.189 & 189 & & & \\
\hline
\end{tabular}

a. $\quad$ R Squared $=.279$ (Adjusted R Squared $=.040$ )

P-values (.000 \& .035) associated with the computed F-values (2109.252 \& 2.957) for intercept and interaction effects of classifying, measuring, and problem-solving skills on posttest scores are all less than .05 . The hypothesis stand rejected for intercept and the science process skills. Table 2 also show that p-values $(.082 \leq$ $\mathrm{P} \leq .983)$ associated with the computed $\mathrm{F}$-values $(.055 \leq \mathrm{F} \leq .3 .065)$ are all higher than .05 . The results therefore show no main and interaction effects for corrected model and science process skills on students' academic performance in practical biology. In this case the null hypothesis was not rejected.

\section{Discussion of findings}

The results of the findings showed a significant interaction effect of acquired science process skills of classifying, measuring and problem-solving skills on students' academic performance in practical biology. This is because the P-values (.000 \& .035) associated with the computed F-values (2109.252 \& 2.957) for intercept and interaction effects of classifying, measuring, and problem-solving skills on posttest scores are all less than .05 . Because the result is significant, the null hypothesis was rejected. However, for science process skills of drawing and observation, the effects were not significant. This is because the $p$-values $(.082 \leq p \leq .983)$ associated with the computed F-values $(.055 \leq \mathrm{F} \leq 3.065)$ are all higher than .05 . The study finding is in line with the study of Richard (2013) who reported a significant effect of science process skills on students' academic improvement. Also, the study by Daramola and Olutola (2016) corroborates with the present study since their findings on comparative 
effect of science process skills on students' academic performance reported a significant effect. Their findings on a comparative effect of science process skills on students' academic performance in Biology in Ilorin, Nigeria reported a significant effect. This means that acquisition of large number of skills influence students' academic performance. Eric (2013) also reported a significant effect of SPS on students' academic performance. The implication therefore is that, acquisition of SPS in large numbers has significant effect on students' learning outcome in practical components of science subjects. The findings of this study however contradict Raj and Devi (2014) who reported a non-significant effect on academic performance but rather sees science process skills acquisition as tools for facilitating the process of learning.

Nonetheless, the significant interaction effect as reveal in this study could be attributed to the facts that students may have reasonably acquired science process skills which must have imparted positively on their academic performance in practical biology. Again, prior training of biology teachers that participated in the study may have increased the students chances of acquiring SPS with greater confidence to tackle practical problems and hence, improvement in academic performance in practical biology.

\section{Conclusion}

From the findings of the study, is concluded that acquired skills of classifying, measuring and problem-solving significantly interact with students' academic performance in practical biology. Furthermore, the study has projected biology to both teachers and students as an action as oppose to one of mere talking and listening. On the basis of the findings, it was concluded that; Acquired classification, measurement and problem-solving skills only showed significant interaction effect on students' academic performance in practical Biology.

\section{Recommendations}

Based on the above findings and conclusions of the study, the following recommendations are made:

1. Biology teachers should imbibe classroom practices that will enhance acquisition of all science process skills as to bring about the desired learning outcome in learners.

2. Stakeholders involved in the formulation and implementation of policies in the realm of science education in Nigeria should realize the significance of science process skills and uphold its tenet because "hear and forget, see and remember, do and understand" is widely accepted as the ideal for science teaching and learning in contemporary secondary school classrooms.

3. Teachers should also select curricula which emphasize science process skills and also ensure that such activities are done in the classroom.

\section{References}

Aka, S. \& Aydogdu, P.A. (2010). Science processes. Be scientific in your society. India: Byee \& Standly publisher. American Association for the Advancement of Science (1989). Project 2061: Science for all Americans. Washington, DC

Ango, M. (2002). Mastery of Science Process Skills and their effective use in the teaching of Science: an Edcology of Science in the Nigerian Context. International Journal of Educology 16(1), 11-30

Bena, V. K. (2010). Competencies for analysis and application. $5^{\text {th }}$ Edn. prentice-hall, New Jersey.

Eric, T. W. (2013). Strategies used by Teachers to Improve Students' Mastery of Drawing Skills and Performance in Biology in Bungoma West District, Kenya. Journal of Emerging Trends in Educational Research and Policy Studies. 4 (3), 473-479.

Ibe, E. \& Nwosu A. A. (2003). Effects of Guided Inquiry and Demonstration on Science Process Skills Acquisition among Secondary School Biology Students. Journal of Science Teachers Association of Nigeria. 38(1\&2), 58-63.

Kamba, A. H, Giwa, A. A, Libata I. A, \& Wakkala (2018). The relationship between SPS and students attitude towards Physics in SSS in Aliero Metropolis. African Educational Research Journal 6(3), 107-113

Nwagbo, C. (2008). Effects of Biology Practical Activities on Students Process Skills Acquisition. Journal of Science Teachers Association of Nigeria. 3(2), 6-9.

Nwankwo,F. (2015). Making sciences activity based through acquisition and utilization of science process skills. Journal of research and practice, 14(2), 86-90.

Ozgelen, S. (2012). Student Science Process Skills within a cognitive domain frame work EURASIA Journal of Mathematics, Science \& technology Education, 8(2), 1-17.

Raj, R. G. \& Devi, S. N. (2013).Science Process Skills and Achievement in Science among High School Students. An International Peer Reviewed: Scholarly Research Journal for Interdisciplinary Studies. 2(15). 82-88.

Richard, O. (2013). Science Process Skills; Its Acquisition among Secondary Schools Students in Biology Practical Examination in Kenya. Journal of social science and Humanities. 4 (11). 
Dr. Stephen Akomaye Adah is a senior lecturer in the Department of Curriculum and Instructional Technology of the Cross River University of Technology Calabar, Nigeria. He has been actively involved in teaching and research at both undergraduate and postgraduate levels. His major research interest has been in area of science education with a focus on Chemistry and Biology. He has published many scholarly articles in both local and international journals, with high impact factors.

Mr. Nsikhe Uwa Ikouwem is a young and enthusiastic lecturer in the Cross River State College of Education, Akamkpa, Nigeria. His major research interest is in Science Education, with a focus on Biology. He has published scholarly articles in both local and international journals. 